\title{
Análise dos cardápios elaborados em um município do nordeste paraense
}

\author{
Analysis of the menus produced in a municipality of the \\ northeast paraense
}

\author{
Paula Valente Leão ${ }^{1}$ (D), Rosa Maria Dias ${ }^{1}$ (D), Andrea das Graças Ferreira Frazão ${ }^{1}$ (D), \\ Cláudia Daniele Tavares Dutra Cavalcanti ${ }^{1}$ (D), Isameriliam Rosaulem Pereira da Silva ${ }^{1}$ (D), \\ Marcieni Ataíde Andrade ${ }^{1}$
}

\begin{abstract}
Resumo
Introdução: A alimentação escolar é uma importante estratégia na formação de hábitos alimentares saudáveis. Objetivo: Analisar os cardápios ofertados aos alunos do Ensino Fundamental em Moju-PA e o número de nutricionistas atuantes no Programa Nacional de Alimentação Escolar. Método: Estudo transversal, descritivo e quantitativo realizado em escolas de Ensino Fundamental, no ano de 2015. Analisou-se a composição química dos alimentos dos cardápios, a oferta de frutas, hortaliças, doces e/ou preparações doces e alimentos restritos, e o número de profissionais contratados. Para a análise da composição química, utilizou-se a Tabela Brasileira de Composição de Alimentos, o Instituto Brasileiro de Geografia e Estatística. O consumo e as adequações de macro e micronutrientes foram baseados na Resolução n. ${ }^{\circ}$ 26/2013, considerando $20 \%$ das necessidades nutricionais diárias. Para o número de nutricionistas, considerou-se a Resolução CFN n. ${ }^{\circ} 465 / 2010$. Resultados: O município contou com uma nutricionista e a oferta de 38 cardápios, sendo 60,5\% para área urbana e 39,5\% para área rural. Todos os cardápios estavam inadequados em energia, fibra, macro e micronutrientes. Observou-se oferta baixa de frutas e hortaliças, e elevada oferta de doces e/ou preparações doces, além de alimentos restritos. Conclusão: Constatou-se número baixo de nutricionistas, além de cardápios inadequados.

Palavras-chave: hábitos alimentares saudáveis; planejamento de cardápio; nutricionistas.
\end{abstract}

\begin{abstract}
Background: School feeding is an important strategy in the formation of healthy eating habits. Objective: To analyze the menus offered to elementary school students in Moju / PA and the number of nutritionists working in the National School Feeding Program. Method: A cross-sectional, descriptive and quantitative study was carried out in elementary schools in 2015. The chemical composition of the menus, the offer of fruits, vegetables, sweets and / or sweet preparations, which was restricted to foods and the number of professionals were analyzed. For the analysis of the chemical composition, the Brazilian Table of Food Composition, the Brazilian Institute of Geography and Statistics were used. Macro and micronutrient consumption and adjustments were based on Resolution $26 / 2013$, considering $20 \%$ of daily nutritional needs. For the number of nutritionists, we considered the CFN Resolution No. 465/2010. Results: The city counted on 1 nutritionist and the offer of 38 menus, which $60.5 \%$ for urban area and $39.5 \%$ for rural area. All menus were inadequate concerning to the following aspects: energy, fiber, macro and micronutrient. There was a low supply of fruits and vegetables and a high supply of sweets and / or sweet preparations, in addition to restricted foods. Conclusion: It was found a low number of nutritionists, as well as inadequate menus.

Keywords: healthy eating habits; menu planning; nutritionists.

${ }^{1}$ Instituto Ciências da Saúde, Universidade Federal do Pará (UFPA) - Belém (PA), Brasil.

Trabalho realizado no no município de Moju(Pa), Brasil.

Endereço para correspondência: Paula Valente Leão - Instituto Ciências da Saúde, Universidade Federal do Pará (UFPA), Avenida Generalíssimo Deodoro, 01 Umarizal - CEP: 66050-160 - Belém (PA), Brasil - Email: pvInutri@gmail.com

Fonte de financiamento: A pesquisa foi feita no âmbito de uma Cooperação Técnica (Termo de Execução Descentralizada) entre o CECANE UFPA e 0 Extinto Ministério do Desenvolvimento Agrário (MDA), com recursos federais, que tinha como objetivo realizar assessoria regionalizada para 0 encontro da demanda da alimentação escolar com a produção da agricultura familiar.

Conflito de interesses: nada a declarar.
\end{abstract}




\section{INTRODUÇÃO}

O Programa Nacional de Alimentação Escolar (PNAE) é o programa mais antigo na área de Segurança Alimentar e Nutricional $(\mathrm{SAN})^{1}$, oficialmente criado em 1955 , com a nomenclatura de Campanha de Merenda Escolar ${ }^{2}$. O programa apresenta como objetivo promover o crescimento e o desenvolvimento biopsicossocial, contribuir com o aprendizado e o rendimento escolar, bem como incentivar hábitos alimentares saudáveis de alunos de escolas públicas, incluindo estudantes de escolas indígenas e remanescentes de quilombos ${ }^{3}$.

Para o alcance deste objetivo, a Lei no 11.947/2009 do PNAE determinou seis diretrizes, entre as quais se destaca "o emprego da alimentação saudável e adequada, compreendendo o uso de alimentos variados, seguros, que respeitem a cultura, as tradições e os hábitos alimentares saudáveis, contribuindo para o crescimento e o desenvolvimento dos alunos e para a melhoria do rendimento escolar, em conformidade com a sua faixa etária e seu estado de saúde, inclusive dos que necessitam de atenção específica"3.

O Fundo Nacional de Desenvolvimento da Educação (FNDE) propõe através da Resolução FNDE no 26/2013 normativos que contribuem com a execução das diretrizes e que facilitem o adequado planejamento dos cardápios no âmbito escolar de acordo com a faixa etária, determinando, para estudantes de tempo parcial e integral, necessidades nutricionais de 20 a $70 \%$ do valor energético diário, além do número de refeições a serem ofertadas ao dia, consumo de, no mínimo, três vezes na semana, de frutas e hortaliças, ingestão de doces e/ou preparações doces para, no máximo, duas vezes por semana com valor de $110 \mathrm{kcal}$. O programa proíbe o consumo de bebidas com baixo valor nutricional, como sucos artificiais, chás e refrigerantes, além de incluir a oferta de produtos da agricultura familiar nos cardápios ${ }^{4}$.

Quanto aos produtos da agricultura familiar, a Resolução FNDE $n^{\circ}$ 26/2013 preconiza que, no mínimo, 30\% do recurso financeiro proveniente do FNDE para o PNAE seja utilizado na aquisição de gêneros alimentícios produzidos pela agricultura familiar e do empreendedor familiar rural ou de suas organizações, priorizando-se os assentamentos da reforma agrária, as comunidades tradicionais indígenas e as comunidades quilombolas ${ }^{3}$, tendo, como consequência positiva, o consumo de alimentos mais saudáveis e regionais, que atendam às especificidades de cada local, além do fomento à economia local.

Atrelado à aquisição de alimentos da agricultura familiar, está o incentivo às práticas e aos hábitos locais; entretanto, nem sempre as preparações regionais estão de acordo com o conceito de alimentação saudável ${ }^{5}$. Um estudo mostrou que o charque esteve mais presente nos cardápios da Região Norte quando comparado à oferta de peixes, assim como a predominância de preparações regionais doces no Nordeste teve como consequência a excessiva oferta de açúcar nos cardápios ${ }^{6}$.

Nessa perspectiva, Teo e Monteiro ${ }^{5}$ sugerem um planejamento de cardápios que vise à integração de diferentes dimensões: alimento básico, saudável, pertencente à cultura alimentar local e, minimamente dentro dos limites legais, proveniente da agricultura familiar. Para esses autores, as diretrizes estipuladas para a elaboração de cardápios, a proibição e a restrição de determinados alimentos, assim como o incentivo à compra de alimentos da agricultura familiar, são ações que se traduzem como uma tentativa de minimizar a presença de alimentos processados e ultraprocessados na alimentação escolar, favorecendo o consumo de uma alimentação pautada nos gêneros in natura e minimamente processados, o que favorece o cumprimento dos objetivos do programa.

Dessa forma, incentivar o consumo de alimentação saudável na escola, seja pela oferta de cardápios balanceados, é um meio importante para promoção de hábitos alimentares saudáveis e adequados a saúde dos alunos, o que favorece o maior consumo de frutas e hortaliças, reduz a ingestão de produtos processados e ultraprocessados, auxilia no controle de deficiências nutricionais, como a alta prevalência do excesso de peso e outras doenças e agravos não transmissíveis que podem se estender para a vida adulta, além de fomentar a economia local através da compra de produtos oriundos da agricultura familiar, garantindo assim a segurança alimentar e nutricional dos alunos ${ }^{3,4,7}$, características da Saúde Coletiva.

Diante deste cenário, é importante avaliar os cardápios ofertados na região Nordeste Paraense, dada a escassez de estudos voltados a esta área e sobretudo ao município de Moju-PA. Além disso, é necessário buscar cada vez mais trabalhos voltados ao Programa Nacional de Alimentação Escolar para que se cumpra a legislação e que se atenda, através da alimentação, à qualidade de vida de todos os estudantes, bem como para avaliar os parâmetros numéricos dos profissionais, pois o quadro insuficiente de nutricionistas acarreta em sobrecarga de trabalho e o descumprimento das atividades direcionadas a eles.

\section{MÉTODO}

Trata-se de uma pesquisa do tipo, transversal e descritivo, com característica quantitativa, desenvolvido no município de Moju-PA, durante o ano de 2017.

Moju pertence à Mesorregião do Nordeste Paraense e à Microrregião Tomé-Açu ${ }^{8}$. O município foi selecionado considerando o grande potencial agrícola para atender ao mínimo de 30\% de produtos da Agricultura Familiar (AF), estabelecido pelo PNAE, e pela facilidade de acesso.

O estudo foi desenvolvido buscando dados referentes ao parâmetro numérico de nutricionistas no município tendo como referência os valores preconizados pela Resolução CFN 
n 465/20109. Para análise dos cardápios, utilizou-se a Resolução FNDE no $26 / 2013^{4}$ para o Ensino Fundamental I (6 a 10 anos) e Fundamental II (11 a 15 anos) referente a 20\% do valor nutricional diário.

Para o desenvolvimento do estudo, foi realizado, inicialmente, contato via telefone e e-mail para agendar uma reunião com o(a) Prefeito(a) e nutricionista, para apresentação do Projeto e assinatura do Termo de Pactuação.

Foram realizadas visitas técnicas e entrevista na Secretaria de Educação do município, para identificar o número de profissionais nutricionistas atuantes no PNAE e levantar os cardápios ofertados no ano de 2015 e o Censo Escolar de 2014.

Nos cardápios, foram analisadas: a composição química, a frequência de frutas e hortaliças de, no mínimo, três vezes na semana, e de doces e/ou preparações doces de, no máximo, duas vezes na semana.

Para a análise da composição química dos alimentos, foram considerados o per capita e a frequência dos alimentos ofertados nos cardápios. Foi utilizado o software ${ }^{\circledR}$ Excel, tendo como base de dados para a análise nutricional a Tabela de Composição Nutricional (TACO) ${ }^{9}$ e o Instituto Brasileiro de Geografia e Estatística $(\mathrm{IBGE})^{10}$. A adequação da oferta de macro e micronutrientes foi baseada nas recomendações das necessidades diárias estabelecidas na Resolução FNDE nº 26/20134.

Para analisar a oferta de frutas e hortaliças, e de doces e/ou preparações doces, dividiu-se a oferta mensal por quatro semanas. A análise da adequação também considerou o disposto na Resolução acima citada, que estabelece a quantidade mínima de três porções de frutas e hortaliças por semana (200 g/aluno/semana) e oferta de doces e/ou preparações doces, no máximo, duas porções por semana.

Realizou-se análise descritiva e inferencial pelos Programas Epi Info e Bioestat. Para verificar diferenças entre as médias dos valores de macro e micronutrientes nos cardápios das zonas urbana e rural, utilizou-se o teste t de Student, com nível de significância de $5 \%(\mathrm{p}<0,05)$.
Este estudo faz parte de um projeto maior: “CECANE/UFPA: Promoção da Inclusão de Produtos Alimentares da Agricultura Familiar Local na Alimentação Escolar nos Municípios do Território Nordeste Paraense", em parceria entre Secretaria Especial de Agricultura Familiar e do Desenvolvimento Agrário (SEAD), FNDE e CECANE/UFPA. O trabalho foi submetido à Plataforma Brasil para análise ética com CAAE No 55212315.7.0000.0018.

\section{RESULTADOS}

De acordo com o Censo Escolar da Secretaria Municipal de Educação de Moju-PA, no ano de 2014 foram matriculados 33.264 alunos em 179 escolas municipais. Destes alunos, 18.403 eram do Ensino Fundamental. Quanto ao número de nutricionistas, havia apenas uma profissional atuando como Responsável Técnica (RT) no município para atender a todos os alunos. Em relação aos cardápios, estes eram repetitivos, conforme pode ser observado naqueles ofertados nos meses de maio e junho, bem como nos meses de outubro, novembro e dezembro.

Foram identificados 38 cardápios para o Ensino Fundamental, distribuídos em 23 cardápios para a área urbana e 15 para a área rural. Não foram identificados cardápios para cada faixa etária da modalidade e nem Ficha Técnica de Preparação.

Os cardápios disponibilizados descreviam os per capitas e a frequência de oferta mensal, por área rural e urbana.

As ofertas de calorias (energia), macronutrientes e fibras foram insuficientes em todos os cardápios, sendo que a oferta de lipídeo para o Ensino Fundamental II na área urbana alcançou maior valor $(68,2 \%)$ e a fibra no Ensino Fundamental II, na área rural, o valor mais baixo (18,2\%). Os minerais cálcio, magnésio, ferro e zinco, e as vitaminas A e C também estavam com valores inferiores à recomendação. $\mathrm{O}$ sódio foi o único mineral ofertado em quantidade superior ao estabelecido, chegando a aproximadamente o dobro da recomendação (195,7\%), na área rural, nas duas faixas etárias (Tabelas 1, 2 e 3).

Tabela 1. Adequação de energia, macronutrientes e fibras dos cardápios ofertados na alimentação escolar do município de Moju-PA no ano de 2015, segundo os valores de referência do Programa Nacional de Alimentação Escolar

\begin{tabular}{|c|c|c|c|c|c|c|c|c|c|c|c|c|c|c|c|c|c|c|c|c|}
\hline \multirow{3}{*}{$\begin{array}{l}\text { Categorias } \\
\text { Escolares }\end{array}$} & \multicolumn{20}{|c|}{ Macronutrientes } \\
\hline & \multicolumn{4}{|c|}{ Energia (Kcal) } & \multicolumn{4}{|c|}{ Proteína $(\mathrm{g})$} & \multicolumn{4}{|c|}{ Lipídeos (g) } & \multicolumn{4}{|c|}{ Carboidratos (g) } & \multicolumn{4}{|c|}{ Fibras (g) } \\
\hline & VR & $\mathbf{M}$ & $\begin{array}{c}\% \\
\text { ad }\end{array}$ & $\mathbf{p}$ & VR & $\mathbf{M}$ & $\begin{array}{c}\% \\
\text { ad }\end{array}$ & p & VR & $\mathbf{M}$ & $\begin{array}{c}\% \\
\text { ad }\end{array}$ & p & VR & $\mathbf{M}$ & $\begin{array}{c}\% \\
\text { ad }\end{array}$ & p & VR & $\mathbf{M}$ & $\begin{array}{c}\% \\
\text { ad }\end{array}$ & p \\
\hline \multicolumn{21}{|l|}{ EFI } \\
\hline Urbano & 300 & 152,3 & 50,8 & \multirow{3}{*}{$<0,001$} & 9,4 & 4,8 & 51,1 & \multirow{3}{*}{0,063} & 7,5 & 5,1 & 68,2 & \multirow{3}{*}{$<0,003$} & 48,8 & 22,0 & 45,2 & \multirow{3}{*}{$<0,001$} & 5,4 & 2,0 & 36,8 & \multirow{3}{*}{$<0,001$} \\
\hline Rural & 300 & 115,2 & 38,4 & & 9,4 & 4,1 & 43,8 & & 7,5 & 3,6 & 47,4 & & 48,8 & 16,6 & 34,0 & & 5,4 & 1,1 & 20,5 & \\
\hline EFII & & & & & & & & & & & & & & & & & & & & \\
\hline Urbano & 435 & 152,3 & 35,0 & \multirow{2}{*}{$<0,001$} & 13,6 & 4,8 & 35,3 & \multirow{2}{*}{0,063} & 10,9 & 5,1 & 46,9 & \multirow{2}{*}{$<0,003$} & 70,7 & 22,0 & 31,2 & \multirow{2}{*}{$<0,001$} & 6,1 & 2,0 & 32,6 & \multirow{2}{*}{$<0,001$} \\
\hline Rural & 435 & 115,2 & 26,5 & & 13,6 & 4,1 & 30,3 & & 10,9 & 3,6 & 32,6 & & 70,7 & 16,6 & 23,5 & & 6,1 & 1,1 & 18,2 & \\
\hline
\end{tabular}

Legenda: EFI: Ensino Fundamental I - Faixa etária de 6 a 10 anos; EFII: Ensino Fundamental II - Faixa etária de 11 a 15 anos; VR: Valor de Referência; M: Município; ad: adequação 
A análise da diferença das médias de macro e micronutrientes presentes nos alimentos ofertados nos cardápios das zonas urbana e rural, demonstrou diferença estatisticamente significativa $(p<0,05)$ em todos os valores, exceto no caso dos macronutrientes para a proteína e nos micronutrientes ferro e zinco ( $p>0,05)$.

Nos cardápios destinados à área urbana, foram ofertadas as frutas laranja, banana e açaí; quanto às hortaliças, apenas a abóbora. Não houve oferta de frutas e hortaliças nas escolas da área rural. Entretanto, a oferta de frutas e hortaliças nas escolas da área urbana foi inferior a três vezes na semana, em todos os meses (Quadro 1).

No que tange à oferta de doces e/ou preparações doces, a legislação limita a duas porções por semana, equivalente a $110 \mathrm{kcal} /$ porção. No município, verificou-se a presença de biscoito doce, bolo de tapioca, Mistura para Preparo (MPP) de achocolatado, MPP de mingau de farinha láctea, MPP de mingau de milho com coco, MPP de mingau de milho branco, MPP de mingau de tapioca com coco e sucos de acerola, caju e goiaba distribuídos no Ensino Fundamental urbano e rural. Predominantemente, a frequência de consumo desses alimentos foi baixa nos meses de 2015, sendo que apenas nos meses de fevereiro, agosto e setembro, para o Ensino Fundamental urbano, e em abril, agosto e setembro, para a área rural, que a frequência foi maior que duas vezes na semana (Quadro 2).

Vale ressaltar que não foi possível avaliar o valor energético de cada doce e/ou preparação doce por ausência de Ficha Técnica de Preparo.

Tabela 2. Adequação de minerais dos cardápios ofertados na alimentação escolar do município de Moju-PA no ano de 2015, segundo os valores de referência do Programa Nacional de Alimentação Escolar

\begin{tabular}{|c|c|c|c|c|c|c|c|c|c|c|c|c|c|c|c|c|c|c|c|c|}
\hline \multirow{3}{*}{$\begin{array}{l}\text { Categorias } \\
\text { Escolares }\end{array}$} & \multicolumn{20}{|c|}{ Micronutrientes (Minerais) } \\
\hline & \multicolumn{4}{|c|}{ Cálcio (mg) } & \multicolumn{4}{|c|}{ Magnésio (mg) } & \multicolumn{4}{|c|}{ Ferro $(\mathrm{mg})$} & \multicolumn{4}{|c|}{ Sódio (mg) } & \multicolumn{4}{|c|}{ Zinco (mg) } \\
\hline & VR & $\mathbf{M}$ & $\begin{array}{c}\% \\
\text { ad }\end{array}$ & $\mathbf{p}$ & VR & $\mathbf{M}$ & $\begin{array}{c}\% \\
\text { ad }\end{array}$ & $\mathbf{p}$ & VR & $\mathbf{M}$ & $\begin{array}{c}\% \\
\text { ad }\end{array}$ & $\mathbf{p}$ & VR & $\mathbf{M}$ & $\begin{array}{c}\% \\
\text { ad }\end{array}$ & $\mathbf{p}$ & VR & M & $\begin{array}{c}\% \\
\text { ad }\end{array}$ & $\mathbf{p}$ \\
\hline \multicolumn{21}{|l|}{ EFI } \\
\hline Urbano & 210 & 28,9 & 13,8 & \multirow{2}{*}{$<0,001$} & 37 & 18,4 & 49,8 & \multirow{2}{*}{$<0,001$} & 1,8 & 0,7 & 36,7 & \multirow{2}{*}{0,361} & 400 & 594,9 & 148,7 & \multirow{2}{*}{$<0,001$} & 1,3 & 0,7 & 53,0 & \multirow{2}{*}{1} \\
\hline $\begin{array}{l}\text { Rural } \\
\text { EFII }\end{array}$ & 210 & 15,5 & 7,4 & & 37 & 11,4 & 30,8 & & 1,8 & 0,6 & 33,1 & & 400 & 782,8 & 195,7 & & 1,3 & 0,7 & 51,1 & \\
\hline Urbano & 260 & 28,9 & 11,1 & \multirow{2}{*}{$<0,001$} & 63 & 18,4 & 29,2 & \multirow{2}{*}{$<0,001$} & 2,1 & 0,7 & 31,5 & \multirow{2}{*}{0,361} & 400 & 594,9 & 148,7 & \multirow{2}{*}{$<0,001$} & 1,8 & 0,7 & 38,3 & \multirow{2}{*}{1} \\
\hline Rural & 260 & 15,5 & 5,9 & & 63 & 11,4 & 18,1 & & 2,1 & 0,6 & 28,4 & & 400 & 782,8 & 195,7 & & 1,8 & 0,7 & 36,9 & \\
\hline
\end{tabular}

Legenda: EFI: Ensino Fundamental I: Faixa etária de 6 a 10 anos; EFII: Ensino Fundamental II Faixa etária de 11 a 15 anos; VR: Valor de Referência; M: Município; ad: adequação

Tabela 3. Adequação de vitaminas dos cardápios ofertados na alimentação escolar do município de Moju-PA no ano de 2015, segundo os valores de referência do Programa Nacional de Alimentação Escolar

\begin{tabular}{|c|c|c|c|c|c|c|c|c|}
\hline \multirow{3}{*}{$\begin{array}{l}\text { Categorias } \\
\text { Escolares }\end{array}$} & \multicolumn{8}{|c|}{ Micronutrientes (Vitaminas) } \\
\hline & \multicolumn{4}{|c|}{ Vitamina A $(\mu \mathrm{g})$} & \multicolumn{4}{|c|}{ Vitamina C (mg) } \\
\hline & VR & $\mathbf{M}$ & $\%$ ad & $\mathbf{p}$ & VR & $\mathbf{M}$ & $\%$ ad & p \\
\hline \multicolumn{9}{|l|}{ EFI } \\
\hline Urbano & 100 & 13,5 & 13,5 & \multirow{2}{*}{$<0,001$} & 7 & 6,5 & 92,9 & \multirow{2}{*}{0,004} \\
\hline Rural & 100 & 18,3 & 18,3 & & 7 & 4,7 & 66,6 & \\
\hline \multicolumn{9}{|l|}{ EFII } \\
\hline Urbano & 140 & 13,5 & 9,7 & \multirow{2}{*}{$<0,001$} & 12 & 6,5 & 54,2 & \multirow{2}{*}{0,004} \\
\hline Rural & 140 & 18,3 & 13,0 & & 12 & 4,7 & 38,8 & \\
\hline
\end{tabular}

Legenda: EFI: Ensino Fundamental I: Faixa etária de 6 a 10 anos; EFII: Ensino Fundamental II: Faixa etária de 11 a 15 anos; VR: Valor de Referência; M: Município; ad: adequação

Quadro 1. Frequência de frutas e hortaliças e legumes presentes nos cardápios planejados da alimentação escolar para o Ensino Fundamental Urbano e Rural, no município de Moju-PA, no ano letivo de 2015

\begin{tabular}{|c|c|c|c|c|c|c|c|}
\hline Modalidades & Mês & Frutas & FM & FS & $\begin{array}{l}\text { Hortaliças } \\
\text { e legumes }\end{array}$ & FM & FS \\
\hline \multirow{7}{*}{ Fundamental (Urbana) } & Fevereiro & Laranja & 2 & 0,5 & Abóbora & 4 & 1,0 \\
\hline & Março & Banana & 2 & 0,5 & Abóbora & 2 & 0,5 \\
\hline & Abril & - & - & - & - & - & - \\
\hline & Maio, Junho & Açaí & 1 & 0,12 & - & - & - \\
\hline & Agosto & Açaí & 1 & 0,25 & Abóbora & 3 & 0,75 \\
\hline & Setembro & Açaí & 1 & 0,25 & Abóbora & 3 & 0,75 \\
\hline & Outubro, Novembro, Dezembro & Laranja & 2 & 0,16 & - & - & - \\
\hline Fundamental (Rural) & Fevereiro a Dezembro & - & - & & - & - & - \\
\hline
\end{tabular}

Fonte: Protocolo de pesquisa, 2017.

FM: Frequência Mensal; FS: Frequência Semanal 
Quadro 2. Frequência da oferta de doces e/ou preparações doces na alimentação escolar para o Ensino Fundamental Urbano e Rural, no município de Moju-PA, no ano letivo de 2015

\begin{tabular}{|c|c|c|c|c|}
\hline Modalidades & Mês & Doces e/ou Preparações Doces & FM & FS \\
\hline \multirow{13}{*}{$\begin{array}{l}\text { Fundamental } \\
\text { (Urbano) }\end{array}$} & \multirow{2}{*}{ Fevereiro } & Suco de goiaba + Biscoito Doce & 5 & \multirow{2}{*}{2,25} \\
\hline & & MPP de Mingau de Tapioca com Coco & 4 & \\
\hline & Março & MPP de Mingau de Milho Branco & 6 & 1,50 \\
\hline & \multirow{2}{*}{ Abril } & MPP de Achocolatado + Bolo de Tapioca & 3 & \multirow{2}{*}{1,25} \\
\hline & & MPP de Achocolatado & 2 & \\
\hline & \multirow{2}{*}{ Maio, Junho } & MPP de Mingau de Farinha Láctea & 8 & \multirow{2}{*}{1,75} \\
\hline & & Suco de Acerola + Biscoito Doce & 6 & \\
\hline & \multirow{2}{*}{ Agosto } & MPP de Mingau de Tapioca com Coco & 6 & \multirow{2}{*}{2,25} \\
\hline & & Suco de Caju & 3 & \\
\hline & \multirow{2}{*}{ Setembro } & MPP de Mingau de Tapioca com Coco & 6 & \multirow{2}{*}{2,25} \\
\hline & & Suco de Caju & 3 & \\
\hline & \multirow{2}{*}{ Outubro, Novembro, Dezembro } & MPP de Mingau de Farinha Láctea & 6 & \multirow{2}{*}{1,33} \\
\hline & & Suco de Acerola + Biscoito Doce & 10 & \\
\hline \multirow{13}{*}{$\begin{array}{l}\text { Fundamental } \\
\text { (Rural) }\end{array}$} & \multirow{2}{*}{ Fevereiro } & Suco de Goiaba + Biscoito Doce & 4 & \multirow{2}{*}{2,0} \\
\hline & & MPP de Mingau de Tapioca com Coco & 4 & \\
\hline & Março & MPP de Mingau de Milho com Coco & 6 & 1,5 \\
\hline & \multirow{2}{*}{ Abril } & MPP de Mingau de Tapioca com Coco & 6 & \multirow{2}{*}{2,5} \\
\hline & & MPP de Achocolatado & 4 & \\
\hline & \multirow{2}{*}{ Maio, Junho } & MPP de Mingau de Farinha Láctea & 8 & \multirow{2}{*}{2,0} \\
\hline & & Biscoito Doce + Suco de Acerola & 8 & \\
\hline & \multirow{2}{*}{ Agosto } & MPP de Mingau de Tapioca com Coco & 6 & \multirow{2}{*}{2,5} \\
\hline & & Suco de Caju & 4 & \\
\hline & \multirow{2}{*}{ Setembro } & MPP de Mingau de Tapioca com Coco & 5 & \multirow{2}{*}{2,25} \\
\hline & & Suco de Caju & 4 & \\
\hline & \multirow{2}{*}{ Outubro, Novembro, Dezembro } & MPP de Mingau de Farinha Láctea & 8 & \multirow{2}{*}{1,6} \\
\hline & & Suco de Acerola + Biscoito Doce & 12 & \\
\hline
\end{tabular}

Fonte: Protocolo de pesquisa, 2017.

FM: Frequência Mensal; FS: Frequência Semanal; MPP: Mistura para preparo

\section{DISCUSSÃO}

A inserção do nutricionista como responsável pela alimentação escolar vem desde o ano 1994, com a Lei n. ${ }^{\circ} 8.913 / 1994^{11}$. Entretanto, segundo Peixinho et al. ${ }^{12}$, somente no ano de 2003, com a implantação da Estratégia Fome Zero, o profissional obteve maior visibilidade, tendo em vista que essa estratégia possuía ações voltadas aos hábitos alimentares saudáveis e à segurança alimentar e nutricional dos estudantes.

Neste contexto, duas resoluções vieram reafirmar o profissional nutricionista na alimentação escolar, a Resolução $n^{\circ} 358 / 2005$ do CFN $^{13}$ e a Resolução do CD/FNDE n 32/2006 ${ }^{14}$. A primeira, estabelecendo as atribuições dos nutricionistas, e a segunda, garantindo a responsabilidade técnica. Em 2010, a Resolução no $358 / 2005^{13}$ do CFN foi substituída pela Resolução CFN no 465/2010 ${ }^{15}$, que, além das atribuições, estabelece os parâmetros numéricos de profissionais necessários para o atendimento de todas as modalidades de ensino. A partir das determinações legais, pode-se observar um aumento significativo dos profissionais atuando nos estados e municípios entre os anos de 2003 e 2011, passando de $12 \%$ para $82 \%$, respectivamente ${ }^{16}$.
Neste estudo, os dados sobre o número de profissionais atuantes no município mostraram que apenas uma nutricionista é responsável pela execução do PNAE, para atender 33.264 alunos de todas as modalidades de ensino. É importante registrar que somente no Ensino Fundamental estavam matriculados 18.403 alunos. Logo, é possível perceber a dificuldade do profissional na execução do Programa, visto que, segundo a legislação, haveria necessidade de pelo menos 15 nutricionistas ${ }^{15}$. Por outro lado, o município estudado é predominantemente extrativista, com IDHM de $0,547^{17}$, e dificilmente teria condições de arcar com o número ideal de profissionais. Entretanto, é importante que os gestores municipais sejam sensibilizados para entender a importância de um quadro técnico adequado para a execução do PNAE.

Estes dados corroboram o estudo de Chaves et al. ${ }^{18}$, o qual identificou que a Região Norte tinha o menor número de profissionais de nutrição cadastrados no FNDE, com percentual de $59 \%$, enquanto que a Região Sul possuía cobertura de $79 \%$.

O número insuficiente de nutricionistas reflete de forma negativa no planejamento dos cardápios, uma de suas atribuições obrigatórias, visto que os cardápios planejados não atendiam às 
necessidades diárias de energia, fibras, macro e micronutrientes, assim como não atendiam à oferta semanal de frutas e hortaliças, enquanto que o consumo semanal de doces e/ou preparações doces ultrapassou a recomendação. É importante relatar também que das 160 escolas do município, 89,4\% estavam localizadas na área rural e a maioria não dispunha de energia elétrica, o que possivelmente tenha contribuído para a falta de oferta de frutas e hortaliças nas escolas rurais, além do alto consumo semanal de doces e/ou preparações doces, ultrapassando a recomendação.

Quanto à oferta de macro e micronutrientes, os cardápios ofertados ao EFI urbano conseguiram atender somente à metade das necessidades diárias dos alunos, no que se refere a energia $(50,8 \%)$ e proteínas $(51,1 \%)$. Os lipídios foram os nutrientes de maior oferta, no entanto, ainda abaixo da recomendação (68,2\%). Os cardápios destinados aos alunos do Ensino Fundamental II apresentaram resultados de adequação mais críticos, pois conseguiram atender a menos de 50\% das necessidades diárias de energia e macronutrientes. Situação semelhante foi observada em relação aos micronutrientes. Tanto para os alunos do Ensino Fundamental I quanto para os do Fundamental II das áreas urbana e rural, a oferta de cálcio, magnésio, ferro, zinco, vitaminas A e $\mathrm{C}$ estava muito abaixo da recomendação, não atendendo às necessidades diárias. Cabe ressaltar que a vitamina $\mathrm{A}$ foi o único micronutriente que apresentou maior valor médio nos cardápios da zona rural em relação aos cardápios da zona urbana. Tal fato, possivelmente, pode ser atribuído à maior frequência mensal de polpa de fruta nos cardápios da zona rural.

Chama a atenção a oferta diária de sódio, que estava bem acima da recomendação, com 1,5 a 2 vezes a mais das necessidades diárias. Considerando que crianças e adolescentes possuem hábitos cada vez mais voltados a alimentos processados e ultraprocessados, o consumo dobrado de sódio durante a refeição oferecida na escola pode contribuir com o aumento da pressão arterial. A hipertensão na infância é preocupante, pois vários estudos referem que crianças com níveis pressóricos elevados apresentam maior probabilidade de se tornarem adultos hipertensos ${ }^{19,20}$.

Sabe-se que uma alimentação inadequada em nutrientes ofertada de forma sistemática traz prejuízo para a saúde da criança e do adolescente, interferindo no rendimento escolar, no processo de desenvolvimento e crescimento, além de ser um fator determinante no aparecimento de carências nutricionais ou surgimento de várias manifestações patológicas que repercutirão na vida adulta ${ }^{21,22}$. Além disso, a falta de planejamento adequado dos cardápios oferecidos aos alunos viola os direitos humanos a uma boa alimentação, visto que o PNAE é um programa propagador do Direito Humano à Alimentação Adequada (DHHA) por garantir alimentação saudável, que atenda à cultura, aos hábitos dos alunos ${ }^{23}$. O estado tem como dever garantir este direito à população, contudo, observa-se que, em Moju-PA, este dever não é cumprido.

Possivelmente, a inadequação de micronutrientes encontrada nos cardápios seja em consequência da baixa oferta de frutas e hortaliças. Na análise dos itens dos cardápios, observou-se oferta de frutas somente para os alunos do Ensino Fundamental da área urbana, com frequência menor que uma vez por semana, em nove meses letivos. A situação da oferta de hortaliças foi mais preocupante, visto que foi ofertada somente a abóbora e apenas na área urbana, também com frequência de até uma vez por semana, em quatro meses letivos.

Nos cardápios ofertados ao Ensino Fundamental urbano, nos meses de fevereiro, agosto e setembro, a oferta de doces e/ou preparações doces (D/PD) alcançou frequência de 2,25 vezes por semana. Já na área rural, a frequência foi superior a duas vezes na semana, nos meses de abril, agosto e setembro, variando de 2,25 a 2,5 porções na semana.

Esses dados chamam atenção, pois esses alimentos são ricos em açúcar, que contribui para elevada densidade energética, podendo desencadear obesidade, diabetes tipo 2, doenças do coração ${ }^{24,25}$. Além do quê, alimentos ricos em açúcar são classificados como processados ou ultraprocessados pelo Guia Alimentar da População Brasileira, os quais devem possuir consumo limitado pela população por serem pobres em micronutrientes e fibras ${ }^{26}$.

É importante mencionar o estudo conduzido por Carmo et al. ${ }^{27}$, o qual identificou que 78,2\% dos adolescentes ultrapassaram o consumo máximo de duas vezes na semana de doces e/ou preparações doces por dia, obtendo como média de consumo 3,8 porções diárias. Os adolescentes possuem preferência por alimentos ricos em gordura, sódio e açúcar ${ }^{28}$, bem como as crianças, ambos sendo facilmente influenciados pela globalização do fast food ${ }^{29}$. Dessa forma, pode-se verificar que a escola se faz de suma importância ao contribuir com a oferta de cardápios nutritivos, incentivando o consumo de alimentos saudáveis.

Diante do que foi mencionado, faz-se necessário aumentar o quadro técnico de nutricionistas no município, além de a gestão municipal garantir infraestrutura e condições de trabalho favoráveis aos profissionais, diminuindo a sobrecarga de trabalho e direcionando os nutricionistas a realizarem as suas atribuições dentro do programa. Ressalta-se, ainda, o interesse dos profissionais em buscar informações e atualizações quanto à elaboração de cardápios, atividade específica deste profissional. Assim, desta forma, estes fatores irão contribuir para adequada elaboração dos cardápios que atenda à legislação do PNAE, melhorando o rendimento escolar dos estudantes, bem como na formação de hábitos saudáveis.

É importante mencionar que este estudo apresenta a limitação de comparação com outros métodos empregados 
para avaliação de cardápios, como o Indicador de Qualidade para Cardápios da Alimentação Escolar (IQCAE), reconhecido como um instrumento que atende às normativas do Programa Nacional de Alimentação Escolar e subsidia trabalhos como este. Contudo, o método adotado nesta pesquisa mostrou-se eficiente e válido para descrever a composição dos cardápios ofertados na alimentação escolar do município estudado.

Este trabalho traz sua contribuição no que se refere à escassez de informações referentes à análise da composição nutricional de escolares na Mesorregião Nordeste Paraense.

\section{CONCLUSÃO}

O estudo evidenciou número insuficiente de nutricionistas atuando no município e inadequação na elaboração dos cardápios no que se refere a composição nutricional, oferta de frutas e hortaliças, e doces e/ou preparações doces.

\section{REFERÊNCIAS}

1. Belik W. Políticas públicas, pobreza rural e segurança alimentar. In: Pochmann M, Fagnani E. Mercado de trabalho, relações sindicais, pobreza e ajuste fiscal. São Paulo: LTr; 2007. p. 180-95. (Série Debates Contemporâneos Economia Social e do Trabalho; no. 1).

2. Brasil. Decreto no 37.106 , de 31 de março de 1955. Institui a Campanha de Merenda Escolar. Diário Oficial da União, Rio de Janeiro, 31 de março de 1955 .

3. Brasil. Lei ${ }^{\circ} 11.947$, de 16 de junho de 2009. Dispõe sobre o atendimento da alimentação escolar e do Programa Dinheiro Direto na Escola aos alunos da educação básica; altera as Leis nos 10.880, de 9 de junho de 2004, 11.273, de 6 de fevereiro de 2006, 11.507, de 20 de julho de 2007; revoga dispositivos da Medida Provisória no 2.178-36, de 24 de agosto de 2001, e a Lei no 8.913, de 12 de julho de 1994; e dá outras providências. Diário Oficial da União, Brasília, 16 de junho de 2009.

4. Brasil. Resolução no 26 , de 17 de junho de 2013. Dispõe sobre o atendimento da alimentação escolar aos alunos da educação básica no âmbito do Programa Nacional de Alimentação Escolar - PNAE. Diário Oficial da União, Brasília, 17 de junho de 2013.

5. Teo CRP, Monteiro CA. Marco legal do Programa Nacional de Alimentação Escolar: uma releitura para alinhar propósitos e práticas na aquisição de alimentos. Rev Nutr. 2012;25(5):657-68. http://dx.doi.org/10.1590/S141552732012000500010 .

6. Chaves LC, Mendes PNR, Brito RR, Botelho RBA. O Programa Nacional de Alimentação Escolar como promotor de hábitos alimentares regionais. Rev Nutr. 2009;22(6):857-66. http://dx.doi.org/10.1590/S1415-52732009000600007.

7. Brasil. Lei $n^{\circ} 12.982$, de 28 de maio de 2014. Altera a Lei $n^{\circ} 11.947$, de 16 de junho de 2009, para determinar o provimento de alimentação escolar adequada aos alunos portadores de estado ou de condição de saúde específica. Diário Oficial da União, Brasília, 28 de maio de 2014.

8. Portal Amazonia. Amazônia de A a Z - Moju, munícipio do Pará [Internet] 2016 [citado em 2016 set 09]. Disponível em: http://www.portalamazonia. com.br/secao/amazoniadeaz/interna.php?id=622

9. Núcleo de Estudos e Pesquisas em Alimentação, Universidade Estadual de Campinas. Tabela brasileira de composição de alimentos - TACO. 4. ed. rev. e ampl. Campinas: BookEditora, 2011.
Estes dados revelam a necessidade de uma reorganização no planejamento da gestão municipal para a contratação de mais profissionais habilitados, o que implica, consequentemente, no cumprimento da Resolução $n^{\circ} 465 / 2010^{15}$, a qual preconiza número suficiente de nutricionistas, de acordo com o número de alunos matriculados no município. Além disso, a mesma resolução estabelece 13 atividades obrigatórias ao profissional nutricionista do PNAE, dentre elas a elaboração dos cardápios escolares.

Diante disso, nota-se que, dentre os diversos fatores para a inadequação dos cardápios, destaca-se o número insuficiente de profissionais atuando na área da alimentação escolar.

Assim, dá-se a relevância deste trabalho, pois além de ser pioneiro em Moju-PA, demonstra a necessidade de adequações no quadro técnico e no planejamento dos cardápios que estão sendo ofertados às escolas públicas.

10. Instituto Brasileiro de Geografia e Estatística. Pesquisa de orçamentos familiares 2008-2009: tabela de composição nutricional dos alimentos consumidos no Brasil. Rio de Janeiro: IBGE; 2011.

11. Brasil. Lei no 8.913, de 12 de julho de 1994. Dispõe sobre a municipalização da merenda escolar. Diário Oficial da União, Brasília, 12 de julho de 1994.

12. Peixinho AML. A trajetória do Programa Nacional de Alimentação Escolar no período de 2003-2010: relato do gestor nacional, Ciênc. Saúde Coletiva. 2013;18(4):909-16. http://dx.doi.org/10.1590/S1413-81232013000400002.

13. Brasil. Resolução CFN no 358 de 18 de maio de 2005. Dispõe sobre as atribuições do nutricionista no âmbito do Programa de Alimentação Escolar (PAE) e dá outras providências. Diário Oficial da União, Brasília, 18 de maio de 2005.

14. Brasil. Resolução/FNDE/CD/No 32 de 10 de agosto de 2006. Estabelecer as normas para a execução do Programa Nacional de Alimentação Escolar - PNAE. Diário Oficial da União, Brasília, 10 de agosto de 2006.

15. Brasil. Resolução CFN no 465/2010, de 23 de agosto de 2010. Dispõe sobre as atribuições do Nutricionista, estabelece parâmetros numéricos mínimos de referência no âmbito do Programa de Alimentação Escolar (PAE) e dá outras providências. Diário Oficial da União, Brasília, 23 de agosto de 2010.

16. Brasil. Ministério da Educação. Alimentação escolar [Internet]. Brasília: Fundo Nacional de Desenvolvimento da Educação; 2011 [citado em 2017 fev 16]. Disponível em: http://www.fnde.gov.br/

17. Conselho Econômico e Social das Nações Unidas. Programa das Nações Unidas para o Desenvolvimento no Brasil - PNUD [Internet]. 2010 [citado em 2017 ago 16]. Disponível em: http://www.br.undp.org/content/brazil/ pt/home/operations/about_undp.html

18. Chaves LG, Santana TCM, Gabriel CG, Vasconcelos FAG. Reflexões sobre a atuação do nutricionista no Programa Nacional de Alimentação Escolar no Brasil. Ciênc Saúde Coletiva. 2013 jan/abr;18(4):917-26. http://dx.doi. org/10.1590/S1413-81232013000400003.

19. Chen X, Wang Y. Tracking of blood pressure from childhood to adulthood: A systematic review and meta-regression analysis. Circulation. 2008;117(25):3171-80. http://dx.doi.org/10.1161/CIRCULATIONAHA.107.730366. PMid:18559702. 
20. Samuels J, Bell C, Samuel J, Swinford R. Management of hypertension in children and adolescentes. Curr Cardiol Rep. 2015;17(12):107. http:// dx.doi.org/10.1007/s11886-015-0661-1. PMid:26482750.

21. Moursi MM, Arimond M, Dewey KG, Treche S, Ruel MT, Delpeuch F. Dietary diversity is a good predictor of the micronutrient density of the diet of 6- to 23-month-old children in Madagascar. J Nutr. 2008;138(12):244853. http://dx.doi.org/10.3945/jn.108.093971. PMid:19022971.

22. Steyn NP, Nel J, Labadarios D, Maunder EM, Kruger HS. Which dietary diversity indicator is best to assess micronutrient adequacy in children 1 to 9 y? Nutrition. 2014;30(1):55-60. http://dx.doi.org/10.1016/j.nut.2013.06.002. PMid:24290599.

23. Siqueira, RL, Cotta RMM, Ribeiro RCL, Sperandio N, Priore SE. Análise da incorporação da perspectiva do Direito Humano a Alimentação Adequada no desenho institucional do programa nacional de alimentação escolar. Ciênc Saúde Coletiva 2014;19(1):301-310. http://dx.doi.org/10.1590/141381232014191.2114 .

24. Welsh JA, Sharma A, Cunningham SA, Vos MB. Consumption of added sugars and indicators of cardiovascular disease risk among US adolescents. Circulation. 2011;123(3):249-57. http://dx.doi.org/10.1161/ CIRCULATIONAHA.110.972166. PMid:21220734.
25. World Health Organization. Guideline: sugars intake for adults and children. Geneva: WHO; 2015.

26. Brasil. Ministério da Saúde. Secretaria de Atenção à Saúde. Guia alimentar para a população brasileira. 2. ed. Brasília: Departamento de Atenção Básica; 2014.

27. Carmo MB, Toral M, Silva MV, Slater B. Consumo de doces, refrigerantes e bebidas com adição de açúcar entre adolescentes da rede pública de ensino de Piracicaba, São Paulo. Rev Bras Epidemiol. 2006;9(1):121-30. http://dx.doi.org/10.1590/S1415-790X2006000100015.

28. Garcia GCB, Gambardella AMD, Frutuoso MFP. Estado nutricional e consumo alimentar de adolescentes de um centro de juventude da cidade de São Paulo. Rev Nutr. 2003;16(1):41-50. http://dx.doi.org/10.1590/S141552732003000100005 .

29. Popkin BM. Global nutrition dynamics: the world is shifting rapidly toward a diet linked with noncommunicable diseases. Am J Clin Nutr. 2006;84(2):289-98. http://dx.doi.org/10.1093/ajcn/84.2.289. PMid:16895874.

Recebido em: Mar. 21, 2018 Aprovado em: Jan. 03, 2019 